\title{
ESTUDO DA PRODUÇÃO DE $\beta$-GALACTOSIDASE POR FERMENTAÇÃO DE PERMEADO DE SORO DE LEITE COM Kluyveromyces marxianus
}

\author{
L. N. S. S. FALLEIROS ${ }^{1}$, B. V. CABRAL ${ }^{1}$, M. M. RESENDE ${ }^{1}$ e E. J. RIBEIRO ${ }^{1}$ \\ ${ }^{1}$ Universidade Federal de Uberlândia, Faculdade de Engenharia Química \\ E-mail para contato: larissa_luc@yahoo.com.br
}

\begin{abstract}
RESUMO - A utilização de $\beta$-galactosidase para hidrolisar a lactose presente em produtos lácteos tornou-se comum no alívio dos sintomas de intolerância à lactose, além disso, a enzima $\beta$-galactosidase pode ser usada na síntese de galacto-oligossacarídeos (GOS) a partir da transgalactosilação da lactose do soro de leite. Neste trabalho, a enzima $\beta$ galactosidase foi produzida pelo cultivo do microrganismo Kluyveromyces marxianus em meio de cultura à base de permeado de soro de leite. Para a extração da enzima $\beta$ galactosidase, foi realizado um estudo comparativo de métodos de ruptura, extração química, através da autólise das células utilizando como solvente o clorofórmio e processos de extração mecânica, ruptura em agitador tipo vórtex e em sonificador utilizando pérolas de vidro, e em processador ultrassônico. O estudo comparativo dos métodos de extração mecânica apontou a ruptura em agitador tipo vórtex utilizando uma carga de $1,1 \mathrm{~g}$ de pérolas de vidro por mililitro de suspensão celular com um tempo de ruptura de 30 minutos como sendo o mais eficiente na extração de $\beta$-galactosidade do interior das células de levedura Kluyveromyces marxianus ATCC 46537, alcançando uma atividade enzimática de 11,667 UGl/mL.
\end{abstract}

\section{INTRODUÇÃO}

A enzima $\beta$-galactosidase ( $\beta$-D-galctosídeo galactohidrolase, EC 3.2.1.23) é uma importante enzima utilizada industrialmente na hidrólise de lactose de leite, este dissacarídeo, de baixo poder adoçante, ao ser ingerido por pessoas intolerantes alcança o intestino delgado sem ser afetado e, finalmente, sofre fermentação microbiana no intestino grosso, causando inchaço abdominal e, diarréia e outros distúrbios gastrointestinais (Gekas e López-Leiva, 1985).

A importância da $\beta$-galactosidase vem sendo ressaltada por sua propriedade de gerar derivados de lactose através de transgalactosilação para formar galacto-oligossacarídeos (GOS), considerados alimentos funcionais. Atualmente tem crescido o interesse em obter enzimas com propriedades adequadas para uso industrial e hábeis para produzir GOS, continua sendo um dos aspectos mais importantes. $\mathrm{O}$ espectro de produto obtido durante a conversão da lactose, a ligação entre as unidades galactosil e a eficiência de transgalactosilação dependem da fonte da enzima e das condições físico químicas do ambiente catalítico (Tzortzis e Vulevic, 2009). 


\section{9 a 22 de outubro de 2014 \\ Florianópolis/SC}

A enzima $\beta$-galactosidase pode ser produzida pela levedura Kluyveromyces marxianus, que é reconhecida e considerada como segura (GRAS), podendo ser utilizada na produção de alimentos e fármacos sem oferecer riscos. No entanto, a produção de enzimas ocorre intracelularmente e requer uma etapa de ruptura das células para sua liberação. A ruptura celular é a primeira etapa no processo de isolamento de materiais intracelulares e constitui uma etapa essencial nos processo de downstream, pois qualquer dano causado ao produto nesta etapa inicial pode comprometer e invalidar todos os processos subseqüentes (Caballero et al., 1995).

Diferentes métodos podem ser empregados para extração de proteínas intracelulares, os quais dependem da força física da parede celular dos micro-organismos, localização dentro da enzima, estabilidade e do uso desejado para o composto de interesse (Pandit et al., 2005; Pinheiro et al., 2003). Métodos mecânicos, físicos, químicos, enzimáticos e a combinação destes podem ser aplicados.

O método mais comum de autólise celular para $\beta$-galactosidase de leveduras é o tratamento de uma suspensão de células com agentes químicos capazes de desorganizar a membrana plasmática, como solventes orgânicos, surfactantes, policátions, proteínas básicas, ou soluções com alto poder iônico (Flores et al., 1994). O rompimento manual com pérolas de vidro é um método mecânico que não necessita de grande aparato experimental. Utiliza basicamente pérolas de vidro e o procedimento consta da adição das mesmas em um tubo, contendo suspensão celular. O tubo é agitado vigorosamente por um tempo determinado, obtendo-se a enzima extraída pela força do atrito devido à moagem com pequenas esferas como abrasivos (Medeiros et al., 2008). O rompimento ultrassônico tem sido aplicado em diversos processos de separação, seja como uma etapa de pré-tratamento ou como processo integral, e também como método potencial para acompanhamento de cultivos microbianos. A maior parte das ondas ultrassônicas é dissipada no sistema líquido através de bolhas de cavitação, as quais formam uma espécie de campo, onde ocorre aumento de massa e conseqüente transferência de calor para o meio líquido, produzindo um gradiente de velocidade e criação de uma força capaz de romper as células e liberar a enzima (Bossio et al., 2008).

O objetivo deste trabalho foi estudar métodos de extração de $\beta$-galactosidase do interior das células de levedura Kluyveromyces marxianus ATCC 46537. Foi realizado um estudo comparativo de métodos de ruptura, extração química, através da autólise das células utilizando como solvente o clorofórmio e processos de extração mecânica, em processador ultrassônico, em agitador tipo vórtex e em sonificador.

\section{MATERIAL E MÉTODOS}

\subsection{Micro-organismo}

A enzima $\beta$-galactosidase foi produzida a partir da levedura Kluyveromyces marxianus ATCC 46537, proveniente da Coleção de Culturas Tropicais da "Fundação André Tosello". A cultura foi mantida a $4{ }^{\circ} \mathrm{C}$, em ágar inclinado, extrato de malte e levedura, composto por extrato de levedura $(3,0$ $\mathrm{g} / \mathrm{L})$, extrato de malte $(3,0 \mathrm{~g} / \mathrm{L})$, peptona $(5,0 \mathrm{~g} / \mathrm{L})$, glicose $(10,0 \mathrm{~g} / \mathrm{L})$ e ágar $(20,0 \mathrm{~g} / \mathrm{L})$. 


\section{9 a 22 de outubro de 2014 \\ Florianópolis/SC}

\subsection{Fermentação}

O extrato enzimático foi obtido por fermentação submersa utilizando permeado de soro de leite como fonte de carbono. O meio composto por extrato de levedura $(6,0 \mathrm{~g} / \mathrm{L}),\left(\mathrm{NH}_{4}\right)_{2} \mathrm{SO}_{4}(6,0 \mathrm{~g} / \mathrm{L})$, $\mathrm{KH}_{2} \mathrm{PO}_{4}(5,0 \mathrm{~g} / \mathrm{L}), \mathrm{MgSO}_{4} .7 \mathrm{H}_{2} \mathrm{O}(0,6 \mathrm{~g} / \mathrm{L})$ e permeado de soro de leite em pó, adquirido comercialmente da empresa SOORO, foi preparado em tampão fosfato $10^{-1} \mathrm{M}$ pH 5,5, a fim de se obter uma concentração de lactose de $50 \mathrm{~g} / \mathrm{L}$. A fermentação foi realizada em incubadora rotatória a $180 \mathrm{rpm}, 30^{\circ} \mathrm{C}$ por 48 horas, iniciando com uma concentração de células de $1 \mathrm{~g} / \mathrm{L}$.

\subsection{Determinação da concentração de lactose}

A concentração de lactose foi analisada por cromatografia líquida de alta eficiência em todos os experimentos. $\mathrm{O}$ processo cromatográfico consiste na partição dos componentes de uma mistura entre a fase móvel e a fase estacionária. A amostra foi diluída, filtrada e injetada no sistema cromatográfico, marca Shimadzu, modelo LC-20 ${ }^{\text {a }}$ Prominence, coluna SUPELCOGEL Ca, na qual os componentes são separados e detectados por refração de luz. A solução de arraste utilizada foi água deionizada, o fluxo de bomba $0,5 \mathrm{~mL} / \mathrm{min}$, temperatura do forno de $80^{\circ} \mathrm{C}$ e volume de injeção de 20 microlitros.

\subsection{Determinação de biomassa}

A concentração de biomassa foi estimada a partir da absorbância a $650 \mathrm{~nm}$, convertida em massa seca de células usando o fator de conversão obtido da curva padrão de biomassa seca.

\subsection{Determinação da atividade enzimática}

A atividade enzimática da enzima $\beta$-galactosidase de Kluyveromyces marxianus ATCC 46537 foi determinada pelo método das taxas iniciais da reação de hidrólise de lactose realizada em um reator de mistura com um volume de $75 \mathrm{~mL}$ de uma solução $50 \mathrm{~g} / \mathrm{L}$ de lactose (PA), preparado em tampão lático $\mathrm{pH} 6,5$, a $30^{\circ} \mathrm{C}$ conforme descrito por Santiago et al. (2004). Para cada experimento era adicionada ao reator $5 \mathrm{~mL}$ do sobrenadante obtido após processo de extração da enzima.

A unidade de atividade usada no trabalho foi $\mathrm{UGl} / \mathrm{mL}$, definida como $\mu$ mol de glicose produzida por minuto, por $\mathrm{mL}$ de suspensão enzimática, à temperatura de $30^{\circ} \mathrm{C}, \mathrm{pH} 6,5$, com uma concentração inicial de lactose de $50 \mathrm{~g} / \mathrm{L}$. Para cada experimento foram tomadas cinco amostras do meio reacional no intervalo de cinco em cinco minutos. Cada amostra era colocada em um tubo de ensaio, o qual era tampado e imediatamente colocado em um banho de água em ebulição, por 10 minutos. A glicose formada foi dosada pelo método da glicose-oxidase. A atividade a partir do método das taxas iniciais, para cada reação da hidrólise de lactose, era obtida pela inclinação das equações lineares de concentração de glicose em função do tempo de reação. Os experimentos foram realizados em triplicata para uma maior confiabilidade nos resultados obtidos.

\subsection{Determinação de proteína total}

A determinação da concentração de proteína total foi obtida a partir da determinação da 


\section{9 a 22 de outubro de 2014 \\ Florianópolis/SC}

concentração de nitrogênio total pelo analisador TOC-L da Shimadzu, convertida em proteína total através do fator de conversão obtido pela curva padrão utilizando albumina de soro bovina (BSA) como proteína padrão.

\subsection{Extração da enzima $\beta$-galactosidase de Kluyveromyces marxianus ATCC 46537}

Com o objetivo de avaliar o melhor método de extração da enzima intracelular $\beta$-galactosidase das células de Kluyveromyces marxianus ATCC 46537, em escala de laboratório, foram estudados quatro métodos de rompimento celular, que são descritos a seguir:

Autólise por clorofórmio: a extração da enzima intracelular $\beta$-galactosidase das células de levedura foi realizada utilizando-se clorofórmio (PA) como solvente, conforme procedimento descrito por Santiago et al. (2004). Uma amostra de $80 \mathrm{~mL}$ de meio fermentado foi centrifugado sob refrigeração, a $6000 \mathrm{rpm}$ por 5 minutos $(27200 \mathrm{~g})$. O sobrenadante era reservado para determinação da concentração de lactose e $\mathrm{pH}$ e o decantado foi ressuspendido com tampão fosfato de sódio $10^{-1} \mathrm{M}$ $\mathrm{pH}$ 6,6, sendo novamente centrifugado nas mesmas condições, com o objetivo de promover uma lavagem de células. Após centrifugação, o sobrenadante foi descartado e o decantado ressuspenso em $10 \mathrm{~mL}$ do mesmo tampão e transferido para uma erlenmeyer ao qual era adicionado $2 \%(\mathrm{v} / \mathrm{v}) \mathrm{de}$ clorofórmio (PA). Esta mistura foi mantida em incubadora rotatória a $150 \mathrm{rpm}, 37^{\circ} \mathrm{C}$ por 17 horas.

Ruptura em agitador tipo vórtex: o processo de abrasão foi realizado em agitador tipo vórtex utilizando pérolas de vidro. Foi utilizada uma carga de $1,1 \mathrm{~g}$ de pérolas de vidro com diâmetro entre 0,95 e 1,05 mm para cada mililitro de suspensão celular. O tubo de ensaio contendo a suspensão celular e as pérolas de vidro foi agitado por 30 minutos, com intervalos de 2 minutos em banho de gelo a cada 5 minutos de agitação (Medeiro et al., 2008).

Ruptura em sonicador: a extração em banho ultrassônico foi realizada utilizando uma carga de $1,1 \mathrm{~g}$ de pérolas de vidro com diâmetro entre 0,95 e $1,05 \mathrm{~mm}$ para cada mililitro de suspensão celular. O tubo de ensaio contendo a suspensão celular e as pérolas de vidro foi colocado no banho ultrassônico por 30 minutos, com substituição da água do banho ultrassônico a cada intervalo de 10 minutos de sonificação (Medeiro et al., 2008).

Rompimento ultrassônico: o rompimento ultrassônico foi realizado através de um processador ultrassônico com frequência de $20 \mathrm{kHz}$ e potência máxima de $150 \mathrm{~W}$ utilizando uma micro ponteira de titânio (Mp) (40\% de potência). A suspensão celular foi mantida no processador ultrassônico por 30 minutos, com manutenção do banho de gelo a cada 10 minutos (Lemes et al., 2012).

Os processos de extração por agitador tipo vórtex, sonicador e processador ultrassônico foram realizados a partir de uma suspensão celular da levedura Kluyveromyces marxianus ATCC 46537 . O caldo fermentado foi centrifugado sob refrigeração $\left(27200 \mathrm{~g}, 4^{\circ} \mathrm{C}, 10\right.$ minutos), o sobrenadante era reservado para determinação da concentração de lactose e $\mathrm{pH}$ e o decantado foi ressuspendido com tampão fosfato de sódio $10^{-1} \mathrm{M} \mathrm{pH} \mathrm{7,3} \mathrm{para} \mathrm{obter} \mathrm{uma} \mathrm{suspensão} \mathrm{celular} \mathrm{com} \mathrm{2,62} \mathrm{mg/mL.}$ 
Para obtenção do extrato enzimático clarificado, a suspensão celular, obtida após cada processo de ruptura, foi centrifugada sob refrigeração $\left(27200 \mathrm{~g}, 4^{\circ} \mathrm{C}, 10\right.$ minutos) e o sobrenadante utilizado para determinar a atividade enzimática e o teor de proteínas totais.

\section{RESULTADOS E DISCUSSÃO}

A Tabela 1 apresenta os resultados de atividade enzimática da ruptura das células de Kluyveromyces marxianus ATCC 46537 utilizando diferentes métodos de extração.

Tabela 1 - Resultados de atividade enzimática da ruptura das células de Kluyveromyces marxianus ATCC 46537 utilizando diferentes métodos de extração

\begin{tabular}{|c|c|c|c|}
\hline Método de extração & $\begin{array}{c}\text { Atividade } \\
\text { Enzimática } \\
\text { (UGl/mL) }\end{array}$ & $\begin{array}{c}\text { Concentração } \\
\text { de proteínas } \\
\text { (mg/L) }\end{array}$ & $\begin{array}{c}\text { Atividade } \\
\text { Específica } \\
\text { (UGl/mg }\end{array}$ \\
\hline Autólise por Clorofóna)
\end{tabular}

Como observado na Tabela 1, a ruptura de células de levedura foi alcançada com utilização de todos os métodos testados, sendo observado o maior valor médio para a atividade enzimática quando a ruptura foi realizada por autólise das células utilizando clorofórmio $(20,001 \mathrm{UGl} / \mathrm{mL})$, resultado próximo ao obtido por Santiago et al. (2004) para a mesma levedura. Contudo a utilização deste método é inviável na obtenção de $\beta$-galatosidase de Kluyveromyces marxianus, pelo fato da enzima $\beta$ galatosidase ter sua aplicação na indústria de alimentos, permanecendo no produto final, sendo assim, a ruptura das células de Kluyveromyces não deve ser conduzida por métodos químicos, pois implicaria a necessidade de remoção de contaminantes, aumentado os custos de produção. Por outro lado, os métodos mecânicos e físicos de ruptura celular não implicam em riscos de toxicidade, pois não incluem produtos químicos no extrato enzimático (Kula e Schutte, 1987; Pandit et al., 2005; Medeiros et al., 2008).

Os métodos de ruptura mecânica apresentaram valores inferiores em termos de atividade enzimática quando comparado com o método de extração química, todavia quando analisados os resultados de atividade específica apresentados na Tabela 1 podemos observar que os métodos de ruptura utilizando agitador tipo vórtex e processador ultrassônico alcançaram valores próximos ao obtido quando utilizado o método químico (autólise por clorofórmio).

A influência do tempo nos processos de extração utilizando agitador tipo vórtex e processador ultrassônico, estão apresentados em termos de atividade enzimática (UGl/mL) e atividade específica

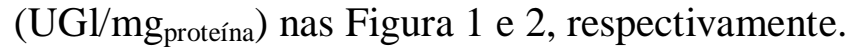

Para a extração usando vórtex, o aumento do tempo implicou em aumento da atividade 
enzimática como observado na Figura 1, contudo quando se analisa a influência do tempo de agitação na atividade específica (Figura 2) verifica-se que o tempo de 30 minutos promoveu o melhor resultado em atividade enzimática específica, ou seja, o melhor resultado de atividade enzimática por miligrama de proteína total. A diminuição da atividade com o aumento no tempo de ruptura para 40 minutos ocorreu devido à desnaturação térmica, pois há geração de calor durante o processo, o que também tem sido verificado por diversos autores (Persike et al., 2002; Tan et al., 2006; Medeiros et al. 2008).

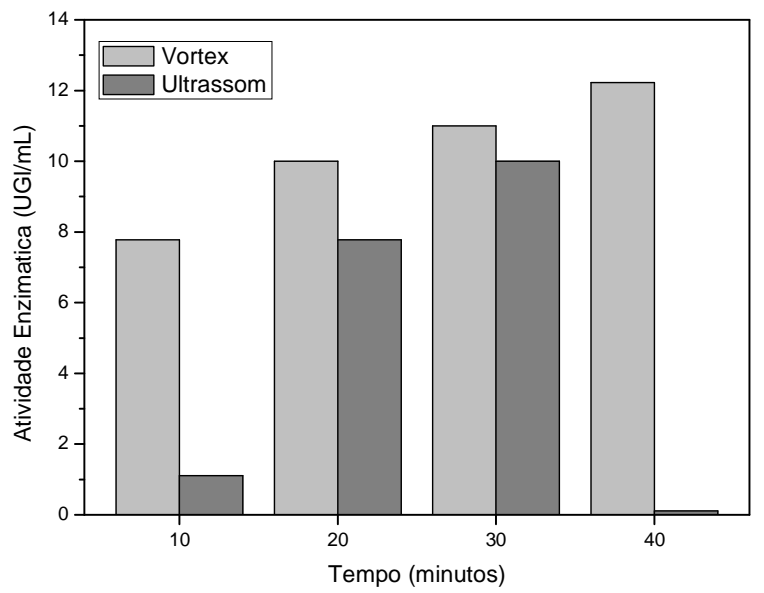

Figura 1 - Influência do tempo nos processos de ruptura em agitador tipo vórtex e processador ultrassônico na atividade enzimática da $\beta$-galactosidase de Kluyveromyces marxianus ATCC 46537.

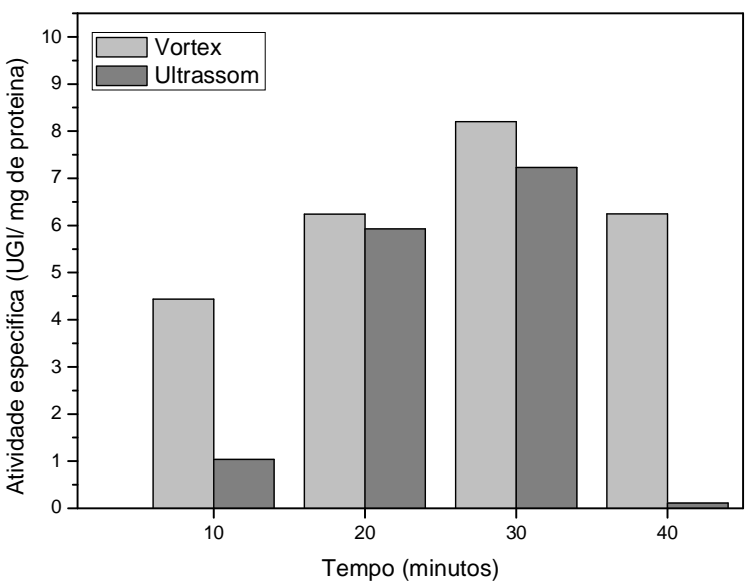

Figura 2 - Influência do tempo nos processos de ruptura em agitador tipo vórtex e processador ultrassônico na atividade específica de $\beta$-galactosidase de Kluyveromyces marxianus ATCC 46537. 


\section{9 a 22 de outubro de 2014 \\ Florianópolis/SC}

De acordo com as Figura 1 e 2, na extração utilizando processador ultrassônico, o aumento do tempo de 10 minutos até 30 minutos de ruptura proporcionou maiores valores para atividade enzimática e específica. O tempo de 40 minutos foi diferente dos demais, observou-se uma queda abrupta da atividade enzimática e específica. A diminuição da atividade ocorreu devido à desnaturação térmica, resultado da dissipação de ondas ultrassônicas e consequente dissipação de calor.

Comparando-se os métodos de ruptura mecânica em agitador tipo vórtex que utiliza pérolas de vidro e o método de extração utilizando processador ultrassônico, ambos foram eficientes no processo de extração de $\beta$-galactosidase do interior das células de levedura Kluyveromyces marxianus ATCC 46537, sendo que o método abrasivo, utilizando pérolas de vidro, apresentou melhores resultados quando comparados com a extração em processador ultrassônico em todos os tempos estudados. Apesar dos ótimos resultados apresentados para ambos os processos de extração, a temperatura durante o processo, dever ser controlada, já que a geração de calor pode resultar em desnaturação da enzima e conseqüentemente perda da eficiência do processo.

Lemes et al. (2012) utilizaram ruptor ultrassônico $(20 \mathrm{KHz}$ e potência máxima de $150 \mathrm{~W})$ com ponteira intermediária (70\% de potência) para utilização em escala laboratorial no processo de extração de $\beta$-galactosidade do interior das células de levedura Kluyveromyces marxianus CCT 7082 e obtiveram resultados em atividade enzimática e rendimentos similares ao método de extração por abrasão que utiliza pérolas de vidro.

Gerde et al. (2012) utilizaram o método de extração ultrassônico para extração de lipídeos do interior da célula de microalgas autotróficas e heterotróficas, o qual se mostrou eficiente. Em ambos os tipos de algas, a extração de material intracelular aumento com o aumento do tempo e da energia dissipada. No entanto, foi constatado que as condições operacionais devem ser bem estabelecidas e controladas, pois o processo sem controle pode resultar na formação de radicais livres que prejudicam a qualidade do óleo extraído neste processo.

\section{CONCLUSÃO}

O método de ruptura química para extrair a enzima $\beta$-galatosidase do interior das células de Kluyveromyces marxianus ATCC 46537, utilizando clorofórmio como solvente, apresentou melhor resultado em atividade enzimática $(20,001 \mathrm{UGl} / \mathrm{mL})$ dentre os métodos analisados, contudo devido a aplicação alimentícia da enzima em questão, seria necessário um etapa posterior para remoção de contaminantes, por outro lado, os métodos mecânicos de ruptura não implicam em toxicidade. Os métodos de ruptura mecânica estudados no presente trabalho alcançaram valores para atividade específica próximos ao obtido quando utilizado o método químico.

\section{AGRADECIMENTO}

Os autores agradecem a UFU e a FEQUI pela oportunidade de realizar este trabalho, ao CNPq e a CAPES pelo apoio financeiro. Agradecemos também à FAPEMIG (Processo PCE-00089-14) pelo apoio concedido. 


\section{9 a 22 de outubro de 2014 \\ Florianópolis/SC}

\section{REFERÊNCIAS}

BOSSIO, J.P.; HARRY, J.; KINNEY, C.A. Application of ultrasonic assisted extraction of chemically diverse organic compounds from soils and sediments. Chemosphere, v. 50, n. 9, p. 858-864, 2008)

CABALlERO, R.; OLGUIN, O.; CRUZ-GUERRERO, A.; GALLARDO, F.; GARCIA-GARIBAY, M.; GBMEZ-RUIZ, L. Evaluation of Kluyveromyces marxianus as baker's yeast. Food Res. Int., v. 28, p. 37-41, 1955.

FLORES, M.V.; VOGET, C.E.; ERTOLA, R.J.J. Permeabilization of yeasts cells (Kluyveromyces lactis) with organic solvents. Enzyme Microb. Technol., v. 16, n. 4, p. 340-346, 1994.

GÉKAS, V.; LOPEZ-LEIVA, M. Hidrolysis of lactose: A Literature Review. Process Biochem., v. 20, p. 2-12, 1985.

GERDE, J.A.; MONTALBO-LOMBOY, M.; YAO, L.; GREWELL, D. WANG, T. Evaluation of microalgae cell disruption by ultrasonic treatment. Bioresour. Technol., v. 125, p. 175-181, 2012.

KULA, M.R.; SCHUTTE, H. Purification of proteins and the disruption of microbial cells. Biotechnol. Progr., v.3, p. 31-42, 1987.

LEMES, A.C.; ÁLVARES, G.T.; KALIL, S.J. Extraction of $\beta$-galactosidase from Kluyveromyces marxianus CCT 7082 by ultrasonic method. Biochem. Biotech. Reports, v. 1, n. 2, p. 7-13, 2012.

MEDEIROS, F.O.; ALVES, F.G.; LISBOA, C.R.; MARTINS, D.S.; BURKERT, C.A.V.; KALIL, S.J. Ondas ultrassônicas e pérolas de vidro: um novo método de extração de $\beta$-galactosidase para uso em laboratório. Quim. Nova, v. 31, n. 2, p. 336-339, 2008.

PANDIT, A.B.; HARRISON, S.; FARKADE, V.D. Heat induced translocation of proteins and enzymes within the cell: an effective way to optimise the microbial cell disruption process. Biochem. Eng. J., v. 23, p. 247-257, 2005.

PERSIKE, D.S.; BONFIM, T.M.; SANTOS, M.H.R.; LYNG, S.M.O., CHIARELLO, M.D. FONTANA, J.D. Invertase and urease activities in the carotenogenic yeastXanthophyllomyces dendrorhous (formerly Phaffia rhodozyma). Bioresour. Technol., v, 82, p. 79-85, 2002.

PINHEIRO, R.; BELO, I.; MOTA, M. Growth and $\beta$-galactosidase activity in cultures of Kluyveromyces marxianus under increased air pressure. Lett. Appl. Microbiol., v. 37, p. 438442, 2003.

SANTIAGO, P.A., MARQUEZ, L.D.S.; CARDOSO, V.L.; RIBEIRO, E.J. Estudo da produção de $\beta$ galactosidase por fermentação de soro de queijo com Kluyveromyces marxianus. Ciência Tecnol. Alimentos, v.24, n. 4, p. 567-572, 2004.

TAN, W.S.; KAMARUDDIN, S.; LING, R.C.; CHEW, T.K.; WOI HO, C. Process Biochem., v.41, p. 1829, 2006.

TZORTZIS, G.; VULEVIC, J. Galacto-oligosaccharide prebiotics. In: Charalampopoulos D, Rastall RA, editors. Prebiotics Probiotics Sci. Technol. New York: Springer, 207-44, 2009. 